\title{
Deficiency in Fat-soluble Vitamins A, D, E in Patients with Pulmonary Multidrug-Resistant Tuberculosis
}

\author{
Lydie Boyvin ${ }^{1,2}$, Bahi Gnogbo Alexis ${ }^{1,2}$, Yayé Yapi Guillaume ${ }^{1,3}$, Séri Kipré Laurent ${ }^{1,2}$, Aké Aya Jeanne \\ Armande $^{1,2}$, Djaman Allico Joseph ${ }^{1,2}$ \\ ${ }^{1}$ Laboratory of Biochemical Pharmacodynamics, University Félix Houphouët-Boigny, Abidjan, Côte d'Ivoire \\ ${ }^{2}$ Clinical \& Basic Biochemistry Department, Institut Pasteur, Abidjan, Côte d'Ivoire, \\ ${ }^{3}$ Biochemistry-Microbiology Department, University Jean Lourougnon Guédé, Abidjan, Côte d'Ivoire,
}

\begin{abstract}
Objective: The treatment management of Multidrug-Resistant Tuberculosis (MDR-TB) is a major global public health problem. The development of this form of tuberculosis increases immune deficiency and the production of free radicals in the body. Micronutrients, especially fat-soluble vitamins $A, D$, and $E$, play an essential role in the immune system by protecting and renewing cells. The objective of this study is to determine the profiles of vitamins $A, D$, and $E$ in order to evaluate the performance of the immune defenses of MDR-TB under second-line anti-TB treatment.
\end{abstract}

Methods: The analysis of vitamins A, D and E was carried out using an HPLC chain, in isocratic mode by UV-Visible detection after prior extraction of the lipid fraction from the serum in the hexane protected away from light.

Results: MDR-TB showed a significant decrease in the concentration of vitamins $A, D$, and $E(p<0.05)$ with high reduction levels of $80 \%, 40 \%$ and $50 \%$, respectively.

Conclusion: The persistence of this deficit after six months of TB treatment highlights the need for corrective measures to be taken, such as the supplementation of vitamins A, D, and E. J Microbiol Infect Dis 2020; 10(4): 199207.

Keywords: Micronutrients, Multidrug-resistant, Tuberculosis, HPLC, Côte d'Ivoire

\section{INTRODUCTION}

Multidrug-Resistant Tuberculosis (MDR-TB) is a life-threatening infectious disease caused by mycobacterium tuberculosis, which is resistant to at least the two major anti-tuberculosis drugs of the first-line treatment, Isoniazid and Rifampicin [1]. MDR-TB is a real threat to the eradication of tuberculosis [2]. About 480,000 people suffered from MDR-TB with 190,000 deaths worldwide [3]. The prevalence of MDRTB in Africa and Côte d'Ivoire is 14\% [4] and $2.5 \%$, respectively [5]. Encountering new resistance and high rates of treatment failure when taking second-line anti-tuberculosis drugs make medical treatment management difficult. This situation severely threatens the Sustainable Development Goals (SDGs) in its efforts to eradicate TB in all its forms by 2030 [6]. In fact, in 2010, the rate of treatment failures was more than $50 \%$; in 2012 , about $9.6 \%$ of these MDR-
TB evolved into a form of Extensive Drug Resistant Tuberculosis (XDR-TB) [3].

MDR-TB is characterized by a reduction in macrophage phagocytic activities, a decrease in lymphocytes proliferation and a reduction in erythropoiesis [7,8]. Additionally, the increased oxidative stress caused by mycobacterial infection during the inflammatory process contributes to the deterioration of the immune cells [9].

Another characteristic of mycobacterium tuberculosis infection, the causative agent of tuberculosis, is the differentiation of infected macrophages into foamy cells rich in lipids [10]. These cells accumulate lipid droplets, lipid storage that are necessary for intracellular bacillary growth [11] probably by their ability to provide mycobacteria with micronutrients (vitamins and trace elements) that are essential

Correspondence: Dr. Boyvin Lydie, Laboratory of Biochemical Pharmacodynamics, University Félix Houphouët-Boigny, Abidjan, Côte d'Ivoire 
for the proper functioning of the human body [10].

The antioxidant and immunostimulant properties of vitamins $A, D$ and $E$ have been the subject of several studies in recent years. Vitamins $A$ and $D$ are essential for the normalization of lymphocytes B and $T$ cell functions, antibody production and macrophage activation [12, 12]. Vitamin $E$ increases lymphocyte proliferation and phagocytic activity of macrophage cells. It also protects the integrity of immune cells against free radical aggression [13]. Therefore, supplementation with these micronutrients in MDR-TB cases taking TB treatment may help to selectively strengthen important parts of their immune defenses [14]. Given the importance of these fat-soluble vitamins in the fight against tuberculosis, studying the relationship between micronutrients and MDR-TB is vital to improve the medical treatment management of the MDRTB patients.

Therefore, this study therefore is a preliminary study with the aim of contributing to the better management of patients with MDR-TB. The overall goal was to evaluate the disorder of fatsoluble vitamins $A, D$ and $E$ in patients with MDR-TB.

\section{METHODS}

\section{Study Design, Site and Study Population}

This is an experimental study carried out on MDR-TB patients from the pneumology section of the University Teaching Hospital (UTH) in Cocody and in the five anti-tuberculosis centers (ATC) in the city of Abidjan (Abobo, Adjamé, Koumassi, Port-Bouet and Yopougon). Informed consent was obtained from patients for the use of their blood.

This study was conducted from January 2014 to December 2015, at the Institut Pasteur of Côte d'Ivoire (IPCI) which is one of the biological monitoring centers for MDR-TB patients.

The samples included in this study were taken from 100 patients with MDR-TB after confirmation of resistance to both first-line antiTB drugs (Isoniazid and Rifampicin) through microscopic and molecular analyses performed by the National TB Reference Laboratory, according to the WHO recommended tests (Gene Xpert) [15,16].
Samples from children, pregnant women and subjects with sensitive TB and HIV positive were excluded from this study.

In the same site, 100 non-tuberculosis samples were collected, which showed no clinicobiological signs of active tuberculosis and who voluntarily accepted to give consent for the use of their blood for research purpose in this study to serve as control subjects. Patients and controls were divided equally into 50 men and 50 women. The age range of all participants is between 18 and 50 years. However, samples from the controls who did not give their consent to participate in this study, samples from children, pregnant women and patients with sensitive tuberculosis were not included in the study.

\section{Collection of samples and reagents}

The biological material consisted of the whole blood of MDR-TB patients being treated and non-tuberculous voluntary controls taken in a dry tube without anticoagulant. Sampling was performed one time only in control subjects and at different stages (M0, M3 and M6) of treatment follow-up in MDR-TB patients.

A total of 300 MDR-TB samples and 100 control samples were collected and used for this study. The samples were centrifuged at $3000 \mathrm{rpm}$ for five minutes using a Horizon 642 VES centrifuge manufactured by The Drucker Co., USA. The sera were collected in Eppendorf $\AA$ tubes and stored at $-20^{\circ} \mathrm{C}$ until the performance of micronutrient analysis.

Reference standard solutions ( $1 \mathrm{~g} / \mathrm{L}$ vitamin A, 1 $\mathrm{g} / \mathrm{L}$ vitamin $D$ and $10 \mathrm{~g} / \mathrm{L}$ vitamin $\mathrm{E})$ and an internal standard (retinyl acetate, $1 \mathrm{~g} / \mathrm{L}$ ) were used to prepare different diluted concentrations from which calibration curves were plotted.

\section{Determination of vitamins $A, D$ and $E$ by HPLC}

The analysis of vitamins $A, D$ and $E$ was carried out using a Waters ${ }^{\circ}$ HPLC chain, USA, in isocratic mode by UV-Visible detection after prior extraction of the lipid fraction from the serum in the hexane protected away from light. The extraction and the determination of the vitamin concentrations were carried out as follows: In a hemolysis tube containing $300 \mu \mathrm{L}$ of serum, $300 \mu \mathrm{L}$ of retinyl acetate (internal standard) prepared at $1 \mathrm{mg} / \mathrm{L}$ [17] and $300 \mu \mathrm{L}$ 
of ethanol were added successively and the mixture was vortexed for 20 seconds. After the homogenization of the mixture, $1200 \mu \mathrm{L}$ of hexane (extraction solvent) was added to the mixture and the whole was again vortexed twice for 30 seconds successively and then centrifuged at $3500 \mathrm{rpm}$ for 15 minutes. Then, $900 \mu \mathrm{L}$ of the supernatant (hexane phase) was recovered and passed through nitrogen gas (pressure: 0.5 bar), to evaporate the solvent. Three hundred microliters $(300 \mu \mathrm{L})$ of methanol (elution solvent) was added to the residue obtained after evaporation. The mixture, obtained by stirring gently, was the extract used for the quantitative analysis of vitamins. Twenty microliters $(20 \mu \mathrm{L})$ of the mixture (residue methanol) was injected automatically into the injection loop of the C18 column in the chromatographic system. The peaks corresponding to the different vitamins $A, D$ and $E$ with retention times of 3.84 minutes, 7.29 minutes and 8.23 minutes are presented on the chromatogram displayed by the recording integrator. Concentrations of vitamins are determined from the peak areas. The chromatographic conditions are as follows: A reverse phase $\mathrm{C} 18$ column by Waters Spherisorb $®$ ODS2 was used as a stationary phase. It is preceded by a precolumn adapted to columns C18. The mobile phase consisted of a mixture of methanol/water $(97 / 3, \mathrm{v} / \mathrm{v})$ at a flow rate of $1 \mathrm{~mL} / \mathrm{min}$ with an injection volume of 20 $\mu \mathrm{L}$. The simultaneous detection of the three vitamins (A, D and E) was carried out at UVVisible at the wavelength of $180 \mathrm{~nm}$, and the analysis of the chromatographic data was done using Breeze 2. Moreover, the detection limits for vitamins $A, D$ and $E$ are $0.005 \mathrm{mg} / \mathrm{L}, 0.006$ $\mathrm{mg} / \mathrm{L}$ and $0.087 \mathrm{mg} / \mathrm{L}$ respectively. Serum reference values are $0.35-1.75 \mu \mathrm{mol} / \mathrm{L}$ for vitamin $A ; 60-105 \mathrm{nmol} / \mathrm{L}$ for vitamin $\mathrm{D}$ and $18-$ $29 \mu \mathrm{mol} / \mathrm{L}$ for vitamin $\mathrm{E}$ [18].

The reduction percentages of vitamins are calculated by this formula:

Reduction $(\%)=[($ Mean of Controls - Mean MDR-TB) / Mean of Controls] x 100

\section{Statistical analysis}

The mean values with the standard error on mean (mean \pm SEM) of the data were calculated using the Graph Pad Prism 5.0 software (Microsoft, USA). The statistical analysis of the results was performed using the ANOVA, followed by the Tukey Multiple Comparison Test. The difference is significant when $p$-value $<0.05$.

\section{RESULTS}

The results showed a significant decrease in the concentrations of vitamins $A, D$ and $E$ in men and women with MDR-TB, both at baseline (M0) and during treatment follow-ups (M3, M6) compared to non-tuberculous controls $(p<0,05)$ (Figure 1 and Table 1). This decrease is revealed by percentages reduction of vitamin concentrations above $80 \%, 40 \%$ and $50 \%$ respectively for the vitamins $A, D$ and $E$ in MDRTB subjects. It should be noted that these reductions in vitamin concentrations are observed in all stages of MDR-TB treatment follow-up (Figure 2).

Therefore, these results showed no significant variation in the concentrations of vitamins $A$ and E during second-line TB treatment (Table I).

The concentration of vitamin $D$ has increased significantly $(p<0.05)$ compared to the baseline stage (Table 1).

However, the concentration of vitamin A in nontuberculosis controls subjects, although within the range of normal values, is significantly lower than the average of usual values $(p<0.05)$.

A comparative analysis of the concentrations of vitamins $A, D$ and $E$ according to sex in the MDR-TB sample (Table II) shows significant decrease in women's concentrations of vitamins $A, E$ at all stages M0, M3, M6, and vitamin D at the M0 stage.

\section{DISCUSSION}

In this study, low concentrations of fat-soluble vitamins $A, D$ and $E$ are observed in MDR-TB sample compared to non-tuberculosis control. This could be explained due to malnutrition [19] and inflammation. In fact, acute and chronic inflammation leads to malabsorption of lipid fractions containing fat-soluble vitamins [20]. Similar vitamin concentration levels have been reported in previous studies in patients with active tuberculosis, particularly in India [21] and Nigeria [22]. Other more specific mechanisms related to the metabolism of each fat-soluble vitamin. Thus, the decrease in serum vitamin $A$ concentrations in MDR-TB may be due to an increase in the urinary excretion of this vitamin 
and a reduction in the hepatic production of its transport to serum, particularly the retinolbinding protein (RBP). This protein is necessary for the plasma mobilization of vitamin A (Retinol) stored in the liver [23]. Furthermore, zinc deficiency and high levels of oxidative stress lead to a high production of oxygen and nitrogen reactive species during mycobacterial infection $[21,24]$.

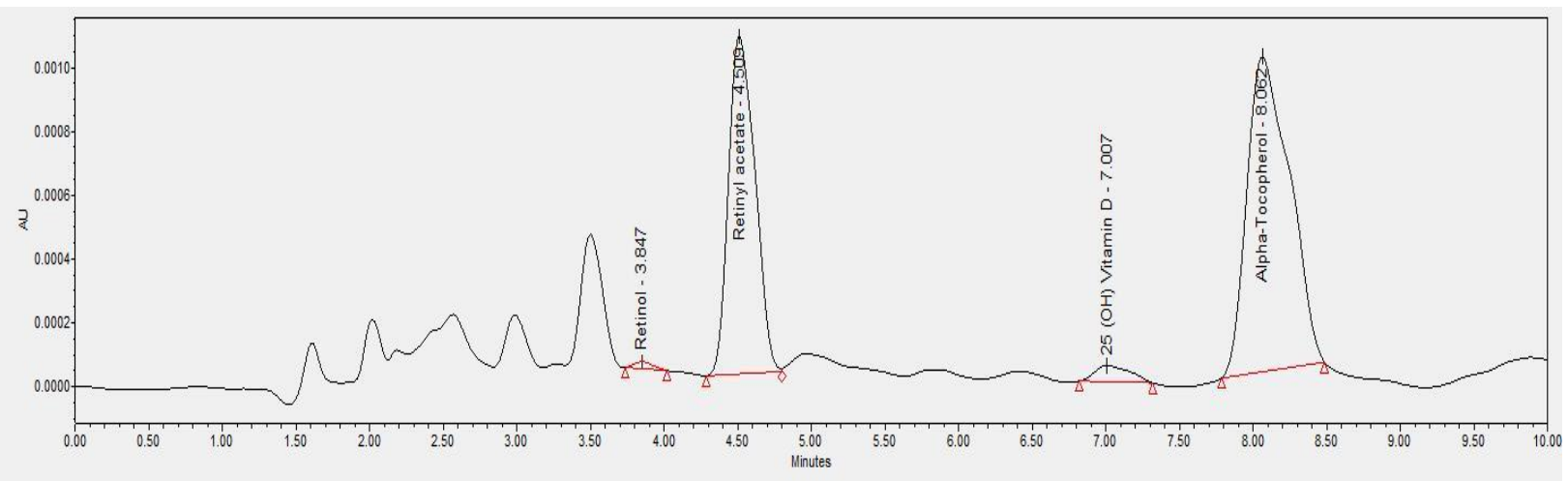

\begin{tabular}{|l|l|r|r|r|r|r|l|}
\hline & Molecules & Retention Time & Area & \% Area & Height & Amount & Units \\
\hline 1 & Retinol & 3.847 & 195 & 0.57 & 22 & 0.600 & $\mathrm{mg} / \mathrm{L}$ \\
\hline 2 & Retinyl acetate & 4.509 & 13237 & 38.68 & 1064 & 9.000 & $\mathrm{mg} / \mathrm{L}$ \\
\hline 3 & $25(\mathrm{OH})$ Vitamin D & 7.007 & 855 & 2.50 & 52 & 1.000 & $\mathrm{mg} / \mathrm{L}$ \\
\hline 4 & Alpha-Tocopherol & 8.062 & 19937 & 58.25 & 988 & 20.000 & $\mathrm{mg} / \mathrm{L}$ \\
\hline
\end{tabular}

Figure 1a. Non-tuberculous controls: Normal profile of vitamins A, D and E in non-tuberculous controls.

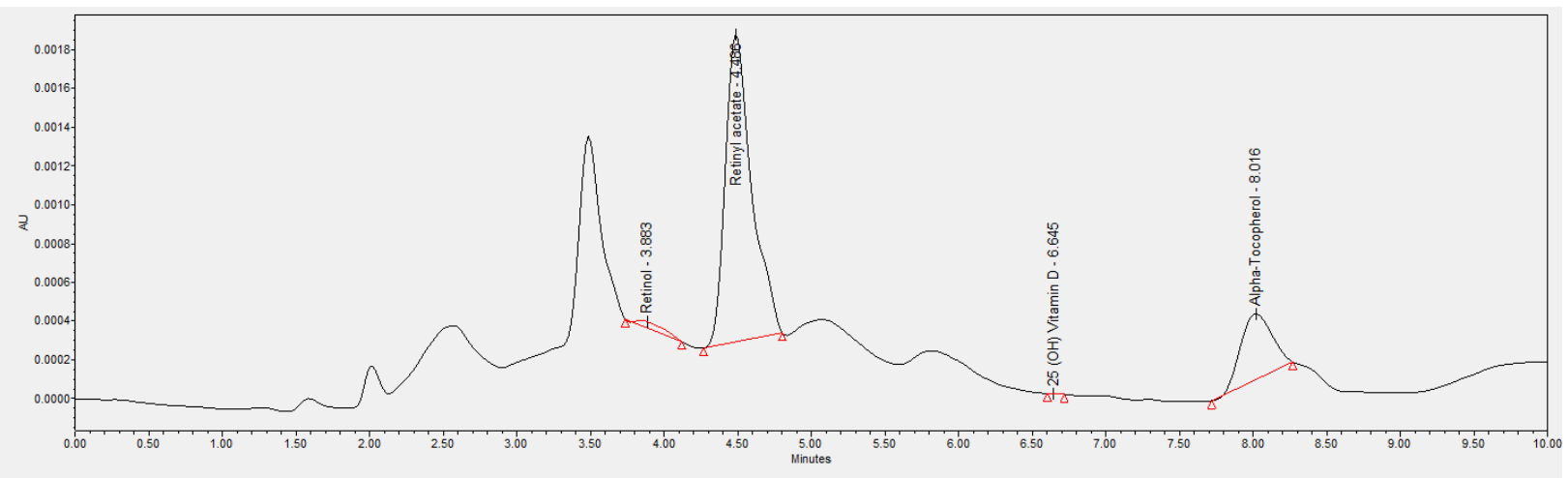

\begin{tabular}{|r|l|r|r|r|r|r|l|}
\hline & \multicolumn{1}{|c|}{ Molecules } & Retention Time & Area & \% Area & Height & Amount & Units \\
\hline 1 & Retinol & 3.883 & 455 & 1.81 & 33 & 0.468 & $\mathrm{mg} / \mathrm{L}$ \\
\hline 2 & Retinyl acetate & 4.486 & 19704 & 78.24 & 1589 & 10.471 & $\mathrm{mg} / \mathrm{L}$ \\
\hline 3 & $25(\mathrm{OH})$ Vitamin D & 6.645 & 4 & 0.01 & 1 & 0.000 & $\mathrm{mg} / \mathrm{L}$ \\
\hline 4 & Alpha-Tocopherol & 8.016 & 5021 & 19.94 & 340 & 3.789 & $\mathrm{mg} / \mathrm{L}$ \\
\hline
\end{tabular}

Figure 1b. MDR-TB patients: Abnormal profile of vitamins A, D and E in MDR-TB patients. 
Table 1. Levels of vitamins A, D and E in MDR-TB patients and non-tuberculous controls.

\begin{tabular}{|c|c|c|c|c|c|}
\hline \multicolumn{2}{|l|}{ Variables } & \multirow{2}{*}{$\begin{array}{c}\text { Control } \\
0.50 \pm 0.21\end{array}$} & \multirow{2}{*}{$\begin{array}{c}\text { MDR-TB Mo } \\
0.10 \pm 0.02^{*}\end{array}$} & \multirow{2}{*}{$\begin{array}{c}\text { MDR-TB M } \\
0.14 \pm 0.02^{*}\end{array}$} & \multirow{2}{*}{$\begin{array}{c}\text { MDR-TB M } 6 \\
0.15 \pm 0.14^{*}\end{array}$} \\
\hline & Vitamin A (Ref.: 0.35-1.75 $\mu \mathrm{mol} / \mathrm{L})$ & & & & \\
\hline \multirow[t]{3}{*}{ Male } & Vitamin D (Ref.: 60-105 nmol/L) & $108 \pm 4.8$ & $13 \pm 2.60^{* \circ}$ & $26 \pm 5.20^{*}$ & $57 \pm 2.60^{*}$ \\
\hline & Vitamin E (Ref.: 18-29 $\mu \mathrm{mol} / \mathrm{L})$ & $24 \pm 5.38$ & $3 \pm 0.90^{*}$ & $6 \pm 1.47^{*}$ & $7 \pm 3.68^{*}$ \\
\hline & Vitamin A (Ref.:0.35-1.75 $\mu \mathrm{mol} / \mathrm{L})$ & $0.44 \pm 0.19$ & $0.08 \pm 0.04^{*}$ & $0.12 \pm 0.08^{*}$ & $0.14 \pm 0.17^{*}$ \\
\hline \multirow[t]{2}{*}{ Female } & Vitamin D (Ref.: 60-105 nmol/L) & $105 \pm 3.40$ & $5 \pm 2.60^{* 0}$ & $26 \pm 5.80^{*}$ & $54 \pm 2.60^{*}$ \\
\hline & Vitamin E (Ref.: 18-29 $\mu \mathrm{mol} / \mathrm{L})$ & $30 \pm 2.87$ & $5 \pm 1.71^{*}$ & $5 \pm 1.35^{\star}$ & $10 \pm 3.48^{*}$ \\
\hline
\end{tabular}

$\mathrm{M}_{0}$ : baseline value; $\mathrm{M}_{3}$ : Value at three months of treatment follow-up; $\mathrm{M}_{6}$ : Value at six months of treatment follow-up

*: Significant difference between MDR-TB and non-tuberculous controls, $P<0.05$

$\circ$ : Significant difference between different stages of follow-up, $\mathrm{P}<0.05$

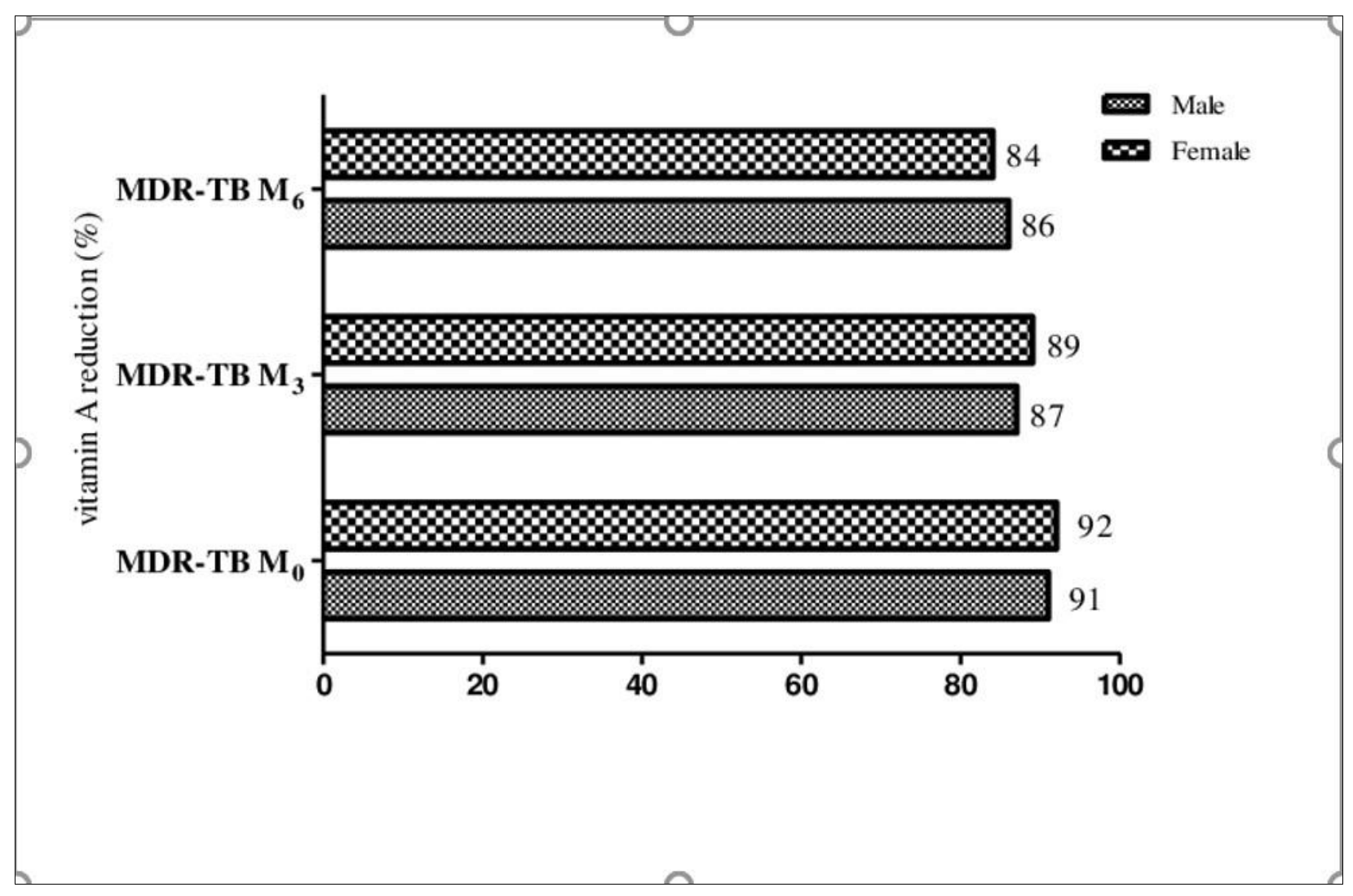

Figure 2a. Vitamin A. 


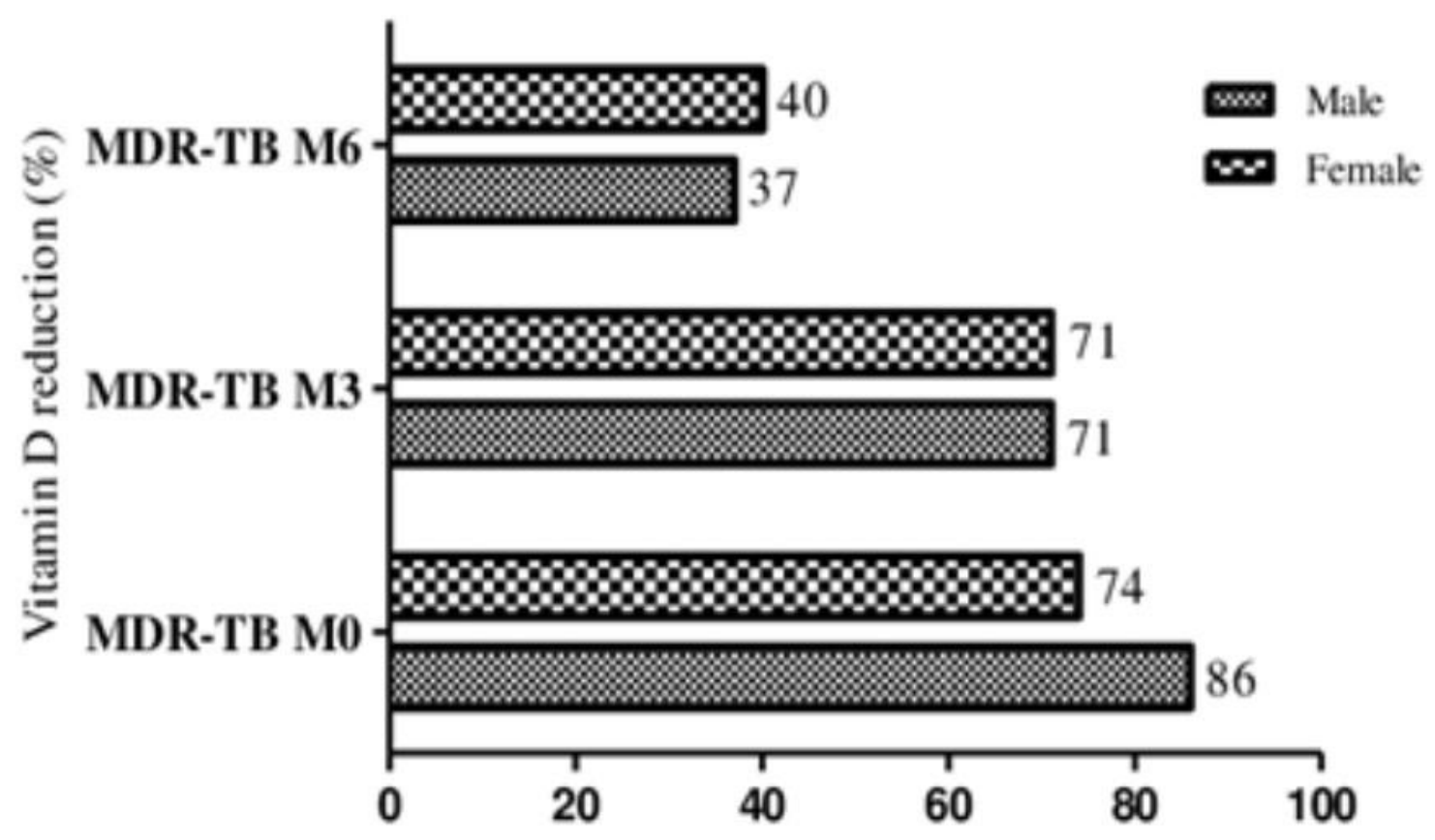

Figure 2b. Vitamin D.

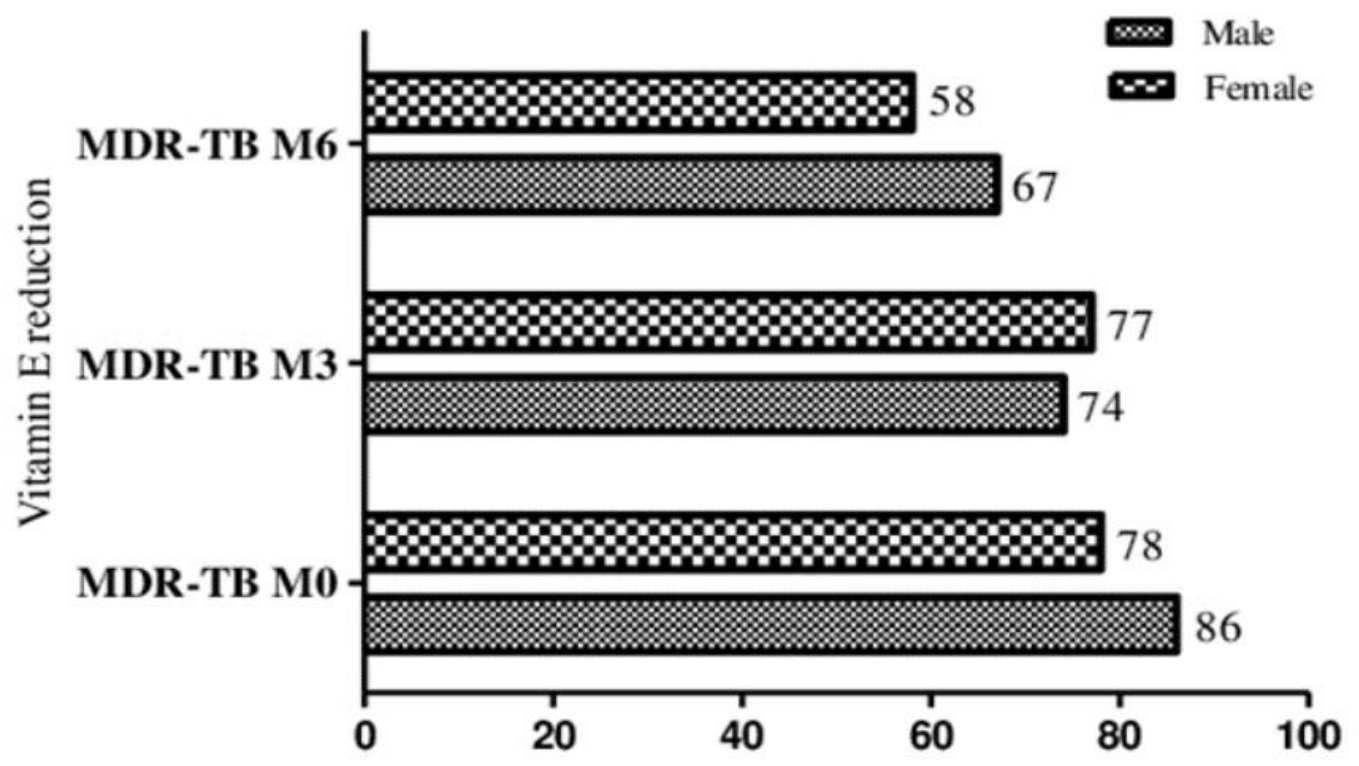

Figure 2c. Vitamin E

Figure 2: Percentages of vitamins A, D and E reduction in MDR-TB patients 
Table 2. Comparative analysis of vitamin concentrations in MDR-TB according to sex.

\begin{tabular}{|c|c|c|c|c|}
\hline Vitamins & Gender & MDR-TB M0 & MDR-TB M3 & MDR-TB $M_{6}$ \\
\hline & Male & $0.10 \pm 0.017$ & $0.14 \pm 0.024$ & $0.15 \pm 0.140$ \\
\hline \multirow[t]{3}{*}{ Vit $A(\mu \mathrm{mol} / \mathrm{L})$} & Female & $0.08 \pm 0.038$ & $0.12 \pm 0.084^{*}$ & $0.14 \pm 0.174$ \\
\hline & $p$-Value & $P=0.002$ & $P=0.001$ & $P=0.003$ \\
\hline & Male & $13 \pm 2.599$ & $26 \pm 5.198$ & $57 \pm 2.599$ \\
\hline \multirow[t]{3}{*}{ Vit D (nmol/L) } & Female & $5 \pm 2.599$ & $26 \pm 5.797$ & $56 \pm 2.599$ \\
\hline & $\mathrm{p}$-Value & $P=0.009$ & $P<0.927$ & $P=0.125$ \\
\hline & Male & $3 \pm 0.901$ & $6 \pm 1.467$ & $8 \pm 3.676$ \\
\hline \multirow[t]{2}{*}{ Vit $E(\mu \mathrm{mol} / \mathrm{L})$} & Female & $5 \pm 1.711$ & $6 \pm 1.346$ & $19 \pm 3.483$ \\
\hline & $p$-Value & $p=0.030$ & $p=0.002$ & $p=0.008$ \\
\hline
\end{tabular}

$\mathrm{M} 0=$ initial baseline stage; $\mathrm{M} 3=$ at three months of treatment follow-up; $\mathrm{M} 6=$ at six months of treatment follow-up

The lower vitamin D concentrations could lead to insufficient nutrient intake, due to a lack of cutaneous synthesis of vitamin D3 and a reduction in the synthesis of its plasma transporter [25, 26]. The most possible explanation would be an abnormality of the vitamin $D$ receptor (VDR). Variations in the polymorphism of the gene encoding vitamin $D$ Binding Protein (VDBP) would result in a reduction of this protein in the plasma transporting vitamin $D$ to the liver [27]. The increase in phosphatemia associated with a reduction in serum calcium and normal creatinemia would exclude the theory of renal failure and would be corroborated with that of hypoparathyroidism secondary to hypovitaminosis D observed in MDR-TB [28].

Vitamin $E$ deficiency is mainly due to the high levels of oxidative stress caused by the overproduction of free radicals of oxygen and nitrogen during bacterial infection [29].

The deficiency of fat-soluble vitamins in MDR-TB patients is more pronounced at the initial baseline stage (M0) before commencement of treatment compared to treatment follow-up stages (M3 and M6). These results are in an agreement with those of Edem et al. [2] who showed an improvement in micro-nutritional status in MDR-TB at four and six months of second-line anti-tuberculosis treatment respectively. Low plasma levels of these fatsoluble vitamins may be one of the main causes of immune deficiency leading to therapeutic failure in MDR-TB patients [13,20, 23].

\section{CONCLUSION}

The persistence of these low concentrations of fat-soluble vitamins $A, D$ and $E$ after six months of the intensive phase of second-line TB treatment requires corrective measures during antibiotic therapy. Supplementation with certain essential micronutrients, especially vitamins $A, D$ and $E$, would stimulate the immune system and restore the balance between the production of free radicals and the antioxidant capacity of these MDR-TB patients. However, additional studies would be needed to better understand the micro-nutritional status of these MDR-TB subjects. More specifically, the serum concentrations of RBP and albumin, which are important in the plasma transportation of vitamin 
$A$ and correlate with serum retinol concentrations, need to be determined. It would also be necessary to evaluate the concentrations and genetic profile of VDBP with the susceptibility of developing active tuberculosis in African populations.

\section{ACKNOWLEDGMENTS}

We thank all of the participants who consented to take part into the present study. We acknowledge the national tuberculosis program for allowing us to be in touch with MDR-TB patients and addressing them to us at the Institut Pasteur Côte d'Ivoire. We thank the head of the Institut Pasteur Côte d'Ivoire, Prof. DOSSO Mireille. We then thank Mr. Ebenezere for his help and inputs in the English version of the current manuscript.

Ethics approval: This study was approved by the National Committee on Ethics and Research of Côte d'Ivoire (NCER). The approval and informed consent were obtained from MDR-TB patients and control participants for the use of their blood for research purpose.

Declaration of Conflicting Interests: The authors declare that they have no conflict of interest.

\section{Funding: Not applicable \\ REFERENCES}

1- WHO: World Health Organization. Principes directeurs à l'intention des programmes antituberculeux pour la prise en charge des tuberculoses pharmacorésistantes. Genève, Suisse, 2008; WHO/HTM/TB/2008, p:402. 276.

2- Edem VF, Ige O, Arinola OG. Plasma vitamins and essential trace elements in multi-drug resistant tuberculosis patients before and during chemotherapy. Egypt $J$ Chest Dis Tuberc 2016; 65: 441-445.

3- WHO: World Health Organization. Global tuberculosis report. Geneva, Switzerland $20^{\text {th }}$ ed, 2015; http://www.who.int/iris/handle/10665/191102. Description. p 192

4- Schaaf H S, Moll A P, Dheda K. Multidrug and extensively drug-resistant tuberculosis in Africa and South America: epidemiology, diagnosis and management in adults and children. Clin Chest Med, 2009; 30: 667-683.

5- Anonyme. Programme National de Lutte Contre la Tuberculose (PNLT), Plan Stratégique National $2012-2015$ de lutte contre la Tuberculose, 2012; p: 65.

6- UN: Union Nation- Projet de document final du Sommet des Nations Unies consacré à l'adoption du programme de développement pour l'après2015. Soixante-neuvième session. New York, Etats Unis, 2015; http://www.adequations.org/spip.php?article2318, p: 38.

7- Shah NS, Moodley P, Babaria P, et al. Rapid diagnosis of tuberculosis and multidrug resistance by the microscopic-observation drug-susceptibility assay, Am J Respir Crit Care Med 2011; 183:142733.

8- Sharma M, Thibert L, Chedore $\mathrm{P}$, et al. Canadian multicenter laboratory study for standardized second-line antimicrobial susceptibility testing of Mycobacterium tuberculosis. J Clin Microbiol 2011; 49: 4112-4116.

9- Prasad AS. Zinc: role in immunity, oxidative stress and chronic inflammation. Clin Nutr Metab Care 2009; 12: 646-52.

10- Russell DG, Cardona PJ, Kim MJ, Allain S, Altare $F$. Foamy macrophages and the progression of the human tuberculosis granuloma. Nat Immunol 2009; 10: 943-8.

11- Simeone R, Sayes F, Song O, et al. Cytosolic Access of Mycobacterium tuberculosis: critical impact of phagosomal acidification control and demonstration of occurrence in vivo. PLoS Pathog 2015; 11 :

12- Eklund D, Persson HL, Larsson M, et al. Vitamin $D$ enhances IL-1b secretion and restricts growth of mycobacterium tuberculosis in macrophages from TB patients. Int. J. Mycobacteriol 2013; 2: 18-25.

13- Pawar BD, Suryakar AN, Khandelwal AS. Effect of micronutrients supplementation on oxidative stress and antioxidant status in pulmonary tuberculosis. Biomed Res 2011; 22: 455-459.

14- Bhootra YM, Babu S. Malnutrition in Tuberculosis. In: Preedy V., Patel V. (eds) Handbook of Famine, Starvation, and Nutrient Deprivation. Springer, Cham 2018; 19 p.

15- Steingart KR, Sohn H, Schiller I, et al. Xpert® MTB/RIF assay for pulmonary tuberculosis and rifampicin resistance in adults. Cochrane Database Systeme 2013; Review 1: CD 009593.

16- N'Guessan KK, Alagna R, Dutoziet CC, et al. Genotyping of mutations detected with GeneXpert. Int J Mycobacteriol 2016; 5: 142-147.

17- Zaman Z, Fielden P, Frost PG. Simultaneous determination of vitamins $A$ and $E$ and carotenoids in plasma by reversed-phase HPLC in elderly and younger subjects. Clin Chem 1993; 39: 2229-34.

18- Beglinger Ch., Seibold F, Rogler G. Valeurs standard en laboratoire. http://www.gastro.medline.ch/Services_et_outils/Val eurs_standard_en_laboratoire/Valeurs_standard_en laboratoire Biochimie.php, 2010, consulté le 02 Septembre 2013. 
19- Martineau AR, Timms PM, Bothamley GH, et al. High-dose vitamin $D(3)$ during intensive-phase antimicrobial treatment of pulmonary tuberculosis: a double-blind randomised controlled trial. Lancet 2011; 377: 242-50.

20- Rajendra $P$, Irfan A, Ram ASK, Wahid A, Mahendra KG, Mohd S. Vitamin A and zinc alter the immune function in tuberculosis. Kuwait Med $\mathrm{J}$ 2012; 44:183-189.

21- Irfan A, Srvasttava VK, Prasad M, Yusuf M, Safia, Saleen M, Wahid A. Deficiency of micronutrient status in pulmonary tubercolosis patients in North India. Biomed Res 2011; 22: 449-454.

22- Edem VF, Ige O, Arinola OG, Plasma vitamins and essential trace elements in newly diagnosed pulmonary tuberculosis patients and at different durations of anti-tuberculosis chemotherapy. Egypt J Chest Dis Tuberc 2015; 64: 675-679.

23- Pakasi TA, Karyadi E, Suratih DNM, et al. Zinc and vitamin $A$ supplementation fails to reduce sputum conversion time in severely malnourished pulmonary tuberculosis patients in Indonesia. Nutr $\mathrm{J}$ 2010; 9: 41.

24- Bahi GA, Boyvin L, Méité S, et al. Assessments of serum copper and zinc concentration, and the $\mathrm{Cu} / \mathrm{Zn}$ ratio determination in patients with multidrug resistant pulmonary tuberculosis (MDR-TB) in Côte d'Ivoire. BMC Infectious Diseases 2017; 17: 257.

25- Nelson CD, Renhardt TA, Beitz DC, Lippolis JD. In vivo activation of the intracrine vitamine $D$ pathway in innate immune cells and mammary tissue during a bacterial infection. PLoS One 2010; 5: e15469.

26- Landrier J F. Vitamine D: sources, métabolisme et mécanismes d'action. OCL 2014; 21: 302-309.

27- Mallet E. Dossier Vitamine D: comment mieux comprendre le métabolisme de la vitamine $D$ ? Réalités Pédiatriques 2013; 181: 16-20.

28- Murry E. Actualités sur la vitamine D et nouvelles perspectives thérapeutiques. Thèse de Doctorat en Pharmacie. Université Joseph Fourier de Grenoble, France 2011; p:125.

29- Bhimrao DP, Adinath NS, Archana SK. Effect of micronutrients supplementation on oxidative stress and antioxidant status in pulmonary tuberculosis. Biomed Res 2011; 22: 455-459. 